\title{
The Influence of Abnormalities in the Profile and Overjet on Psychological Well-Being
}

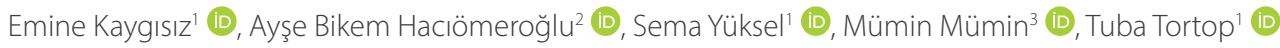

'Department of Orthodontics, Gazi University Faculty of Dentistry, Ankara, Turkey

²Department of Psychology, Ankara Hacı Bayram Veli University Faculty of Literature, Ankara, Turkey

${ }^{3}$ Private Practice, Bursa, Turkey

Cite this article as: Kaygısız E, Hacıömeroğlu AB, Yüksel S, Mümin M, Tortop T. The Influence of Abnormalities in the Profile and Overjet on Psychological Well-Being. Turk J Orthod 2021; 34(1): 54-60.

Main points:

- The effect of abnormalities in the facial profile on children's psychological well-being was not significant.

- Malocclusion type was not a deterministic factor for the psychological well-being of children.

- Early treatment during childhood might be better than late treatment, as malocclusion might affect psychological well-being negatively with aging.

\begin{abstract}
Objective: This study aimed to comparatively evaluate the psychological well-being and health-related quality of life of subjects having either a convex or concave profile and abnormal overjet, with subjects having a straight profile and normal overjet.

Methods: In this study, 163 children and their parents who applied to the Faculty of Dentistry were classified into 3 groups: Group 1: convex profile, Class II molar relationship, and increased overjet ( $n=62 ; 28$ boys and 34 girls; mean age: 11.6 years); Group 2: concave profile, Class III molar relationship, and negative overjet ( $n=55 ; 32$ boys and 23 girls; mean age: 11.2 years); and Group 3: straight profile, Class I molar relationship without crowding, and normal overjet ( $n=46 ; 24$ boys and 22 girls; mean age: 11.0 years). The severity of malocclusion was evaluated using the Index of Orthodontic Treatment Need (IOTN). Self-concept, depression, and state-trait anxiety were evaluated to determine the psychological well-being of the children.
\end{abstract}

Results: No differences were found among the groups with respect to self-concept, depression levels, state-trait anxiety levels, and quality of life scores. No correlation was found between the IOTN scores and psychological well-being.

Conclusion: Abnormalities in the facial profile and negative or increased overjet have no influence on children's psychological well-being.

Keywords: Esthetics, index of orthodontic treatment need, orthodontics, psychology

\section{INTRODUCTION}

Esthetic appearance has a great influence on social interactions and psychological well-being. People satisfied with their faces are more self-confident and have higher self-esteem than those who are dissatisfied (1). As part of the facial structure, dentition plays a crucial role in facial appearance, and people are primarily concerned with their dental appearance, alignment, and arrangement (2). Malocclusion, especially related to anterior teeth, has a psychosocial effect on the well-being, self-confidence, and social life of children and adolescents (3-5). An unattractive dental appearance can hinder adolescents' professional achievements and negatively impact their self-esteem (5). In their 15-year follow-up study, Helm et al. (2) reported that malocclusion may adversely affect self-concept not only during adolescence but also in adulthood.

Gerzanic et al. (6) indicate that psychological profiles are significantly different between Class II and Class III orthognathic surgery patients. Adults with Class III malocclusion felt significantly less attractive and had slightly 
stronger feelings of insecurity regarding their facial appearance compared with Class II patients. However, some authors reported no significant differences between Class II and Class III subjects, who required orthognathic surgery, in their levels of happiness and self-perception of dentofacial attractiveness (7).

In the literature, some studies have evaluated the impact of malocclusion and its severity on the oral-health-related quality of life (OHRQoL). The severity of cases was determined using different indexes, which yielded contradictory results. Ashari and Mohamed (8) have suggested that the Dental Aesthetic Index cannot strongly predict OHRQoL, as there is a significant weak correlation between them. However, Choi et al. (9) concluded that severe malocclusion, as determined according to the Index of Orthodontic Treatment Need (IOTN) was associated with a lower quality of life.

To our knowledge, there is limited number of studies focused on quality of life and, that too, mostly on dental malocclusions, and self-perception of dentofacial attractiveness. (3, 10-12). However, none of them compared the psychological well-being of children with different types of malocclusion. Therefore, this study aimed to comparatively evaluate the psychological well-being (self-concept, depression, and anxiety levels) and health-related quality of life of subjects having a convex or concave profile and abnormal overjet with respect to a control group and to determine the effects with respect to the severity of malocclusion. The null hypothesis was that malocclusion had no effect on psychological well-being of the children.

\section{METHODS}

A total of 163 consecutive children between the ages of 8 and 13, as well as their parents who had attended the Faculty of Dentistry, participated in this study.

The participants were classified into 3 groups based on their profiles (13) and overjets, which were determined by intra- and extra-oral examinations. Overjet was measured between the most anterior point of the maxillary central incisors and the corresponding reference point on the mandibular incisor. The sagittal overjet was measured. A large angle $\left(>10^{\circ}\right)$ between the line extending from the bridge of the nose to the base of the upper lip and the second line dropped from that point downward to the chin indicates profile convexity; an angle less than $10^{\circ}$ shows a concave facial profile, which indicates a skeletal Class III relationship. The participants considered to have a straight profile had a nearly straight line and only a slight inclination in either direction between these line segments (13).

Subjects in Group I had a convex profile, increased overjet, and Class II molar relationship ( $\mathrm{n}=62 ; 34$ girls and 28 boys; mean age: $11.6 \pm 1.47$ years); subjects in Group II had a concave profile, negative overjet, and Class III molar relationship ( $n=55 ; 23$ girls and 32 boys; mean age: $11.2 \pm 1.61$ years); and subjects in Group III had a straight profile, normal overjet without crowding, and Class I molar relationship ( $\mathrm{n}=46 ; 22$ girls and 24 boys; mean age: $11.0 \pm 1.75$ years) (Figure 1).
The Ethics Committee of the University approved the study (604.01.02/50), and informed consent was obtained from the parents of the children who agreed to participate in this study. Although a sample size of 37 patients per group at $\mathrm{a}=0.05$ yields a statistical power of 0.80 for this study, the sample size was increased to at least 46 patients per group. Therefore, the realized power of this study was obtained as $87 \%$ with a significance level of 0.05 and an effect size of 0.27 . Patients who had craniofacial anomalies such as cleft lip and/or palate, facial asymmetry, missing or impacted teeth except third molars, medical problems, temporomandibular joint pain, orthodontic treatment experience, untreated caries, periodontal disease, and any psychiatric diagnosis were excluded from the study.

We evaluated 10 malocclusion traits to determine the Dental Health Component of the IOTN (DHC-IOTN) (14). These traits were overjet, reverse overjet, overbite, open bite, crossbite, crowding, impeded eruption, cleft lip and palate defects or other craniofacial anomalies, Class II and Class III buccal occlusions, and hypodontia. The DHC-IOTN consists of 5 grades: grades 1 and 2 indicate no need for treatment, grade 3 indicates borderline cases, and grades 4 and 5 indicate those who need orthodontic treatment.

Clinical evaluations and the DHC-IOTN measurements were conducted by one author (E.K). After the clinical evaluations, participants were evaluated in terms of their psychological well-being (state and trait anxiety, depression, self-concept, and health-related quality of life). The Piers-Harris Children's Self-Concept Scale (PHCSC), Children's Depression Inventory (CDI), and State-Trait Anxiety Inventory for Children (STAIC) were used to assess the children's psychological well-being. To measure health-related quality of life, the Pediatric Quality of Life (PedsQL) Inventory was administered to children and parents, separately and simultaneously.

The PHCSC was developed by Piers and Harris (15) to assess self-concept in children. The PHCSC is a self-report questionnaire consisting of 80 yes/no items. The sum of the affirmative answers, with one point assigned to each, yields the final score. The higher the score, the more positive the respondent's self-image. The PHCSC is composed of 6 domain scales: behavioral adjustment, intellectual and school status, physical appearance and attributes, freedom from anxiety, popularity, and happiness

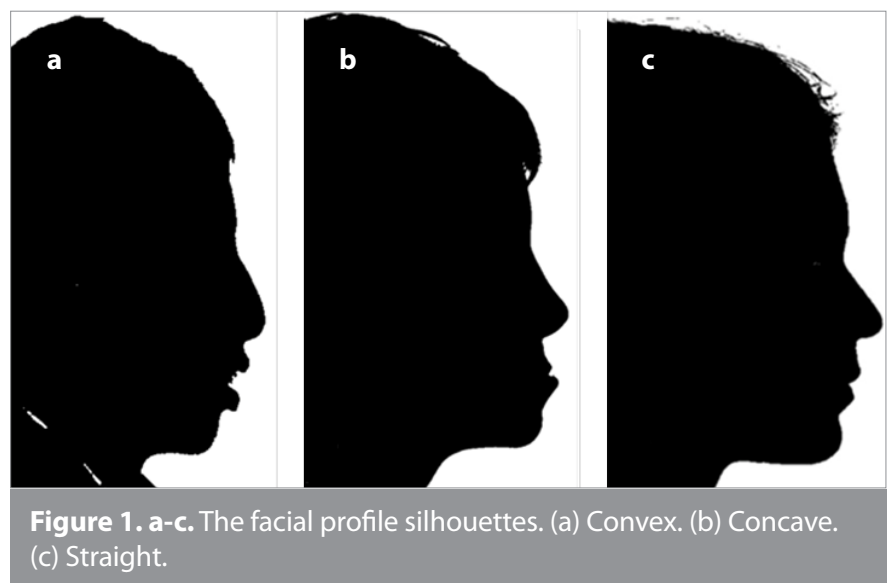


and satisfaction. The Turkish adaptation study of the PHCSC was conducted by Öner (16). The reliability coefficients of the Turkish form range from 0.81 to 0.89 (16).

CDI was used to assess the depression levels of children (17). CDI is a 27-item self-report scale, in which items are rated between 0 and 2. A higher total score demonstrates a greater severity of depressive symptomatology. The reliability and validity study of the Turkish version of CDI was verified by Öy (18). Test-retest reliability and criterion-related validity were found to be 0.80 and 0.61 , respectively (18).

STAIC consists of two 20-item scales that measure state and trait anxiety in children between the ages of 8 and 14 (19). The A-State scale examines the shorter-term state anxiety that is commonly specific to situations. The A-Trait scale measures longer-term trait anxiety, which addresses how the child generally feels. The statements are rated from 1 to 3, with a total score of 20-60 for each scale. The Turkish reliability and validity study of this inventory was conducted by Özusta (20). The Cronbach's alpha coefficient was 0.82 for the State scale and 0.81 for the Trait scale (20).

The PedsQL measures the health-related quality of life in healthy children and adolescents, as well as in those with acute and chronic health conditions (21). The 23-item scale measures physical, emotional, social, and school functioning. PedsQL scales comprised child self-reports (ages 5-7, 8-12, and 13-18) and parent proxy reports, which assess parents' perceptions of their children's health-related quality of life. Physical health scores, psychosocial health scores, and total scores were obtained from the scale. Higher scores indicate better health-related quality of life. Memik et al. (22) adapted the Turkish versions of this scale. The Cronbach alpha coefficients range from 0.59 to 0.88 (22).

\section{Statistical Analysis}

Statistical analysis was performed using the Statistical Package for Social Sciences, version 16.0 software (SPSS Inc;; Chicago,IL, USA). Ages and the scores obtained from the questionnaires of the groups were statistically compared using one-way analysis of variance. The gender difference in the scores was determined with the Student $t$-test. The relationships among the IOTN scores, psychological well-being, and health-related quality of life were examined using the Spearman rank correlation coefficient. Intra-examiner reliability for the aesthetic component scale of the IOTN (AC-IOTN) was evaluated by Kappa analysis. The significance level was set to $p<0.05$.

\section{RESULTS}

The mean age was found to be similar among the groups. There was high agreement between the first and second readings for the AC-IOTN obtained by the same examiner $(r=0.89)$. There was no statistically significant gender difference in terms of state and trait anxiety, depression, self-concept, and health-related quality of life scores (Table 1).

The results revealed that state and trait anxiety levels were similar in both malocclusion groups, and these values showed no differences between the malocclusion and control groups.
No significant differences were found among the groups with respect to depression levels (Group 1: 7.06; Group 2: 7.56; and Group 3: 7.28) and self-concept (Group 1: 65.33; Group 2: 65.19; and Group 3: 65.28). In terms of quality of life total scores, physical health, and psychosocial health scores, the self-report of the children did not differ significantly in the 3 groups. Although parents' self-reports with regard to the quality of life total scores, physical health, and psychosocial health scores were higher in the convex profile with increased overjet cases than for the concave profile with negative overjet and control groups, there were no significant differences among the groups (Table 2).

The distribution of IOTN scores in Groups 1 and 2 is given in Table 3. In Group 1, 43.5\% of subjects were in the category of grade 4, as were $56.4 \%$ of subjects in Group 2. Among the IOTN scores

Table 1. Gender differences in state and trait anxiety, depression, self-concept, and health-related quality of life scores (Student's t-test)

\begin{tabular}{|c|c|c|c|c|}
\hline $\begin{array}{l}\text { Psychological } \\
\text { status and } \\
\text { quality } \\
\text { of life } \\
\text { parameters }\end{array}$ & $\begin{array}{c}\text { Male } \\
(n=84) \\
\text { Mean } \pm S D\end{array}$ & $\begin{array}{c}\text { Female } \\
(n=79) \\
\text { Mean } \pm \text { SD }\end{array}$ & $\mathbf{p}$ & \\
\hline State anxiety & $29.74 \pm 6.63$ & $29.34 \pm 6.37$ & 0.700 & NS \\
\hline Trait anxiety & $32.75 \pm 5.39$ & $33.81 \pm 7.06$ & 0.280 & NS \\
\hline Depression & $7.73 \pm 5.72$ & $6.91 \pm 7.07$ & 0.420 & NS \\
\hline Self-concept & $65.49 \pm 8.22$ & $65.04 \pm 10.51$ & 0.770 & NS \\
\hline $\begin{array}{l}\text { Child report- } \\
\text { quality of life } \\
\text { total score }\end{array}$ & $80.63 \pm 12.24$ & $82.61 \pm 12.87$ & 0.320 & NS \\
\hline $\begin{array}{l}\text { Child report- } \\
\text { physical health score }\end{array}$ & $81.48 \pm 13.83$ & $81.42 \pm 16.18$ & 0.980 & NS \\
\hline $\begin{array}{l}\text { Child report- } \\
\text { psychosocial } \\
\text { health score }\end{array}$ & $79.38 \pm 14.20$ & $82.90 \pm 13.59$ & 0.110 & NS \\
\hline $\begin{array}{l}\text { Parent report- } \\
\text { quality of life } \\
\text { total score }\end{array}$ & $75.00 \pm 16.18$ & $76.31 \pm 15.28$ & 0.600 & NS \\
\hline $\begin{array}{l}\text { Parent report- } \\
\text { physical health score }\end{array}$ & $75.74 \pm 18.98$ & $75.24 \pm 19.67$ & 0.870 & NS \\
\hline $\begin{array}{l}\text { Parent report- } \\
\text { psychosocial } \\
\text { health score }\end{array}$ & $75.30 \pm 15.02$ & $76.62 \pm 15.36$ & 0.580 & NS \\
\hline $\begin{array}{l}\text { Parent report- } \\
\text { psychosocial } \\
\text { health score }\end{array}$ & $75.30 \pm 15.02$ & $76.62 \pm 15.36$ & 0.580 & NS \\
\hline
\end{tabular}

Table 2. The distribution of IOTN scores in Groups 1 and 2

\begin{tabular}{|lcccccccc|} 
& \multicolumn{2}{c}{ Group 1 } & & \multicolumn{2}{c}{ Group 2 } & & \multicolumn{2}{c|}{ Total } \\
\cline { 2 - 3 } IOTN scores & $\mathbf{n}$ & $\%$ & & $\mathbf{n}$ & $\%$ & & $\mathbf{n}$ & $\%$ \\
\hline 2.00 & 11 & 17.7 & 2 & 3.6 & & 13 & 11.1 \\
3.00 & 14 & 22.6 & & 19 & 34.5 & & 33 & 28.2 \\
4.00 & 27 & 43.5 & 31 & 56.4 & 58 & 49.6 \\
5.00 & 10 & 16.1 & 3 & 5.5 & & 13 & 11.1 \\
Total & 62 & 100.0 & 55 & 100.0 & & 117 & 100.0 \\
\hline
\end{tabular}


Table 3. The comparison of the 3 groups in terms of psychosocial well-being and quality of life of the children and their parents (one-way analysis of variance)

\begin{tabular}{|c|c|c|c|c|c|c|}
\hline $\begin{array}{l}\text { Psychological status and } \\
\text { quality of life parameters }\end{array}$ & $\begin{array}{c}\text { Group } 1 \\
\text { Mean } \pm \text { SD }\end{array}$ & $\begin{array}{c}\text { Group } 2 \\
\text { Mean } \pm \text { SD }\end{array}$ & $\begin{array}{c}\text { Group } 3 \\
\text { Mean } \pm \text { SD }\end{array}$ & $F(2,160)$ & $\mathbf{p}$ & \\
\hline State anxiety & $31.06 \pm 8.26$ & $29.00 \pm 5.65$ & $28.89 \pm 5.54$ & 1.770 & 0.170 & NS \\
\hline Trait anxiety & $34.71 \pm 6.70$ & $32.98 \pm 6.35$ & $32.36 \pm 5.63$ & 1.890 & 0.150 & NS \\
\hline Depression & $7.06 \pm 5.22$ & $7.56 \pm 5.81$ & $7.28 \pm 5.56$ & 0.060 & 0.920 & NS \\
\hline Self-concept & $65.33 \pm 10.26$ & $65.19 \pm 9.80$ & $65.28 \pm 8.21$ & 0.003 & 0.990 & NS \\
\hline Child report-quality of life total score & $81.47 \pm 14.63$ & $83.47 \pm 10.94$ & $79.53 \pm 12.37$ & 1.420 & 0.240 & NS \\
\hline Child report-psychosocial health score & $80.31 \pm 16.03$ & $82.77 \pm 13.44$ & $79.80 \pm 12.77$ & 0.740 & 0.470 & NS \\
\hline Parent report-quality of life total score & $74.41 \pm 8.93$ & $78.60 \pm 11.70$ & $73.31 \pm 16.44$ & 1.860 & 0.150 & NS \\
\hline Parent report-physical health score & $73.76 \pm 21.93$ & $78.20 \pm 15.80$ & $73.88 \pm 20.39$ & 0.990 & 0.370 & NS \\
\hline Parent report-psychosocial health score & $76.49 \pm 16.51$ & $78.40 \pm 12.11$ & $72.68 \pm 16.68$ & 2.140 & 0.120 & NS \\
\hline
\end{tabular}

Table 4. The correlations among the IOTN scores and the psychological well-being and health-related quality of life of the patients and parents (Spearman's rank correlation coefficient)

\begin{tabular}{|c|c|c|c|c|c|c|c|c|c|c|c|c|}
\hline \multicolumn{3}{|c|}{$\begin{array}{l}\text { Psychological } \\
\text { status and } \\
\text { quality of } \\
\text { life parameters }\end{array}$} & \multirow{2}{*}{$\begin{array}{c}\begin{array}{c}\text { State } \\
\text { anxiety }\end{array} \\
0.129\end{array}$} & \multirow{2}{*}{$\begin{array}{c}\text { Trait } \\
\text { anxiety } \\
-0.169\end{array}$} & \multirow{2}{*}{$\begin{array}{c}\begin{array}{c}\text { Self- } \\
\text { concept }\end{array} \\
0.022\end{array}$} & \multirow{2}{*}{$\begin{array}{c}\text { Depression } \\
0.027\end{array}$} & \multirow{2}{*}{$\begin{array}{c}\begin{array}{c}\text { Parent } \\
\text { report- } \\
\text { quality } \\
\text { of life } \\
\text { total score }\end{array} \\
-0.065\end{array}$} & \multirow{2}{*}{$\begin{array}{c}\text { Parent } \\
\text { report- } \\
\text { physical } \\
\text { health } \\
\text { score } \\
0.098\end{array}$} & \multirow{2}{*}{$\begin{array}{l}\begin{array}{c}\text { Parent } \\
\text { report- }\end{array} \\
\text { psychosocial } \\
\text { health } \\
\text { score } \\
-0.203\end{array}$} & \multirow{2}{*}{ 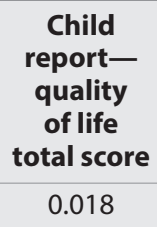 } & \multirow[t]{2}{*}{$\begin{array}{c}\text { Child } \\
\text { report- } \\
\text { physical } \\
\text { health } \\
\text { score } \\
-0.031\end{array}$} & \multirow{2}{*}{$\begin{array}{c}\text { Child } \\
\text { report- } \\
\text { psychosocial } \\
\text { health } \\
\text { score } \\
0.000\end{array}$} \\
\hline IOTN & Group 1 & $r$ & & & & & & & & & & \\
\hline & & $\mathrm{p}$ & 0.318 & 0.189 & 0.866 & 0.833 & 0.615 & 0.446 & 0.114 & 0.887 & 0.810 & 0.997 \\
\hline & & & NS & NS & NS & NS & NS & NS & NS & NS & NS & NS \\
\hline & & $\mathrm{p}$ & 0.702 & 0.436 & 0.579 & 0.162 & 0.678 & 0.623 & 0.794 & 0.829 & 0.415 & 0.962 \\
\hline & & NS & NS & NS & NS & NS & NS & NS & NS & NS & NS & \\
\hline
\end{tabular}

and state-trait anxiety, depression, self-concept, and health-related quality of life scores, none of the correlation coefficients were found to be significant (Table 4).

\section{DISCUSSION}

People who are dissatisfied with their facial appearance often express more displeasure with their teeth than with any other facial feature (1). Adults with severe malocclusion report feeling that they are useless, shameful, and inferior (23). Dibiase and Sandler (24) have suggested that children with certain malocclusions are more likely to be the victims of bullying, such as teasing and name-calling. It has been reported that bullying experiences can impact not only concurrent but also future psychosocial actions (25). The effect of malocclusion on health-related quality of life has been widely evaluated in the literature $(3,5,9)$. However, there are few studies considering psychological well-being of subjects $(3,10-12)$, and to our knowledge, none of them compared psychological well-being and health-related quality of life scores of children who have various malocclusions. Therefore, this study aimed to comparatively evaluate the psychological well-being of the subjects with normal and abnormal profile and overjet, and also determine the effects of the severity of malocclusion, which was assessed with the DHC-IOTN.
Children's feelings about their dental appearance begin to emerge by about 8 years of age. They have criteria similar to those of adults regarding the self-perception of body image (3). According to Rossini et al. (26), the smile appears to be of primary esthetic importance for children younger than 10 years of age as well as for adolescents. It is critical to evaluate the effect of malocclusion on psychological well-being in this age group, as it might influence their future psychosocial life. Therefore, this study researched an age group between 8 and 13 years, which are the critical years in terms of the development of body image and self-perception.

Although some studies have reported a relationship between socioeconomic status and OHRQoL, others have shown no such association $(5,27,28)$. Therefore, to eliminate the possible confounding effects of socioeconomic status on psychological well-being, only participants with similar health insurance plans were included in this study. This allowed us to standardize the socioeconomic status of the participants. However, parents' education levels, incomes, and occupations were not included in the survey, which was a limitation of our study.

Kragt et al. (29) pointed out the importance of sociocultural structures on the perception of dental esthetics. In this study, all 
participants were from the same country and region. Moreover, in some studies, it was reported that no significant differences were found between genders regarding the impact of malocclusion on OHRQoL $(3,30)$. In this study, there were also no significant differences between male and female participants in self-concept, depression, state, and trait anxiety levels. Hence, both genders were evaluated together in each group.

Few studies have examined the relation between self-concept, self-esteem, and malocclusions. Seehra et al. (31) reported that being bullied was significantly associated with a Class II Division 1 incisor relationship and increased overjet, and bullied participants reported lower levels of general self-esteem. In addition, Kenealy et al. (32) reported that malocclusions had a negative impact on the self-esteem of adolescents. Average T-scores for 11 - and 12-year-old subjects were given as 51.3 (33). However, in this study, the mean self-concept scores are higher than the average score, and no significant differences were found among the groups with respect to self-concept. In accordance with our study, Phillips and Beal (10) suggested that an adolescent's self-perception of the dentofacial region has more effect on self-conception issues compared with malocclusion.

No study has evaluated the relation between malocclusion and depression. Bang et al. (34) reported a cutoff score of 15 for mildly depressed subjects. In the present study, it was found that depression scores of adolescents were low (approximately 7 for all groups), and there was no significant difference among the groups. Therefore, it could be interpreted that malocclusion was not a main factor for depression.

The State Anxiety Scale evaluates a subject's current state of anxiety, asking how subjects feel "right now," using items that measure subjective feelings of apprehension, tension, nervousness, worry, and activation/arousal of the autonomic nervous system. The Trait Anxiety Scale evaluates relatively stable aspects of "anxiety proneness," including general states of calmness, confidence, and security (35). In this study, mild state (Group 1: 31.06; Group 2: 29.00; and Group 3: 28.89) and trait (Group 1: 34.71; Group 2: 32.98; Group 3: 32.36) anxiety were observed in all groups, but no significant difference was found with respect to both anxiety scores. As all cases were referred to the clinic for a dental examination, the mild state anxiety might have been due to dental examination fear and anxiety.

Dahong et al. (36) reported that the psychosocial impacts on patients with dental malocclusions were significantly different from those with normal occlusion. However, there is a conflict in the literature about the levels of happiness, concerns and awareness, feelings of insecurity, self-perception regarding facial profile, and dental appearance of adult cases $(7,36)$. In a previous study, adults with a mild protrusion of the lip had significantly better self-esteem and health-related quality of life scores compared to severe protrusion cases (37). This result might indicate a risk of psychosocial impairment if the patients leave without treatment.

A previous study indicated that overjet is one of the most important occlusal traits and might greatly affect the self-dental percep- tion of patients (4). Dahong et al. (36) suggested that this trait, which can be perceived easily by patients, can further influence the psychology of young adults. The researchers reported that the psychosocial impacts of Class III and Class II/I patients were similar, but the effects of these malocclusions were found to be more severe compared with Class I cases. In addition, Johnston et al. (7) reported that psychosocial impacts occurred regardless of the type of malocclusion. In this study, no differences in the psychological well-being of children were found between children with increased, decreased, or normal overjet. The findings of this study were in agreement with those of previous studies, which found that malocclusion type was not a deterministic factor for psychological well-being. However, our findings conflict with previous studies, in which malocclusion groups were compared with control groups. This might be because of the age of the subjects. Kragt et al. (29) reported that children older than 14 years showed the greatest impact of malocclusion on OHRQoL owing to the major life changes occurring between the ages of 11 and 14 years. Choi et al. (9) reported that aging and severity of malocclusion had relatively negative effects on OHRQoL and noted that subjects in their 30s had a more negative perception. In light of the results of this study, it could be concluded that the effect of malocclusion on health-related quality of life did not seem to be significant in the early ages. Therefore, early treatment during childhood might be better than late treatment, as malocclusion might affect psychological well-being negatively with aging.

A systematic review found a missing association between DHCIOTN or index of complexity, outcome, and need and OHRQoL, where an association was found between the AC-IOTN and the social emotional domain of OHRQoL (29). In addition, Baram et al. (38) reported a relationship between AC-IOTN and the psychosocial impact of malocclusion. In a study evaluating the relation between self-esteem and malocclusion, self-esteem was not found to be significantly different between cranial types, but there was a significant difference between the malocclusion severity levels assessed by DHC-IOTN (39). Another study reported that components of IOTN had a maximum impact on self-esteem (40). However, the cases in this study were mostly scored at grade 4, while the correlation between the DHC-IOTN scores and the state-trait anxiety, depression, self-concept, and health-related quality of life scores was found to be insignificant. This inconsistency with previous studies might be due to age difference.

In light of these findings, the null hypothesis could not be rejected because no differences were found among the groups with respect to self-concept, depression levels, state-trait anxiety levels, and quality of life scores.

We were not able to classify and statistically compare the subjects' psychological well-being according to the severity of their profile abnormalities owing to limited sample size.

\section{CONCLUSION}

Abnormalities in the facial profile and negative or increased overjet have no influence on children's psychological well-being. The null hypothesis was accepted. 
No correlation was found between the severity of malocclusion and psychological well-being.

Ethics Committee Approval: This study was approved by Ethics committee of Gazi University, (Approval No: 77082166-604.01.02/50).

Informed Consent: Written informed consent was obtained from the patients who agreed to take part in the study.

Peer-review: Externally peer-reviewed.

Author Contributions: Supervision - E.K., T.T.; Design - E.K., T.T., A.B.H., S.Y.; Resources - M.K, E.K.; Materials - M.K., E.K., T.T..; Data Collection and/ or Processing - E.K., T.T., M.K.; Analysis and/or Interpretation - T.T., E.K., S.Y., A.B.H., S.Y.; Literature Search - E.K., A.B.H., T.T.; Writing Manuscript T.T., E.K., A.B.H.; Critical Review -E.K., T.T., M.K., S.Y., A.B.H.

Conflict of Interest: The authors have no conflict of interest to declare.

Financial Disclosure: The authors declared that this study has received no financial support.

\section{REFERENCES}

1. Berscheid E, Walster E, Bohrnstedt G. Body image. Psychol Today 1973; 7: 119-31.

2. Helm S, Kreiborg S, Solow B. Psychosocial implications of malocclusion: A 15-year follow-up study in 30-year-old Danes. Am J Orthod 1985; 87: 110-8. [Crossref]

3. Sardenberg F, Martins MT, Bendo CB, Pordeus IA, Paiva SM, Auad $S M$, et al. Malocclusion and oral health-related quality of life in Brazilian school children. Angle Orthod 2013; 83: 83-9. [Crossref]

4. Bernabe' E, Flores-Mir C. Influence of anterior occlusal characteristics on self-perceived dental appearance in young adults. Angle Orthod 2007; 77: 831-6. [Crossref]

5. Marques LS, Ramos-Jorge ML, Paiva SM, Pordeus IA. Malocclusion: esthetic impact and quality of life among Brazilian schoolchildren. Am J Orthod Dentofacial Orthop 2006; 129: 424-7. [Crossref]

6. Gerzanic L, Jagsch R, Watzke IM. Psychologic implications of orthognathic surgery in patients with skeletal Class II or Class III malocclusion. Int J Adult Orthodon Orthognath Surg 2002; 17: 75-81.

7. Johnston C, Hunt O, Burden D, Stevenson M, Hepper P. Self-perception of dentofacial attractiveness among patients requiring orthognathic surgery. Angle Orthod 2010; 80: 361-6. [Crossref]

8. Ashari A, Mohamed AM. Relationship of the Dental Aesthetic Index to the oral health-related quality of life. Angle Orthod 2016; 86: 33742. [Crossref]

9. Choi SH, Kim JS, Cha JY, Hwang CJ. Effect of malocclusion severity on oral health-related quality of life and food intake ability in a Korean population. Am J Orthod Dentofacial Orthop 2016; 149: 38490. [Crossref]

10. Phillips C, Beal KNC. Self-concept and the perception of facial appearance in children and adolescents seeking orthodontic treatment. Angle Orthod 2009; 79: 12-6. [Crossref]

11. Jha K, Saha S, Gv J, Narang R, Biswas G, Sood P, et al. Prevalence of Malocclusion and its Psycho-Social Impact among 12 To 15-Yearold School Children in Lucknow City. J Clin Diagn Res 2014; 8: 36-9. [Crossref]

12. Martins-Júnior PA, Marques LS, Ramos-Jorge ML. Malocclusion: social, functional and emotional influence on children. J Clin Pediatr Dent 2012; 37: 103-8. [Crossref]
13. Proffit WR, Fields HW, Sarver DM, editors. Contemporary Orthodontics. 5th ed. St Louis: Mosby; 2014.

14. Brook PH, Shaw WC. The development of an index of orthodontic treatment priority. Eur J Orthod 1989; 11: 309-20. [Crossref]

15. Piers EV, Harris DB. Age and other correlates of self-concept in children. J Educ Psychol 1964; 55: 91-5. [Crossref]

16. Öner N. Piers-Harrissin çocuklar için öz kavram ölçeği el kitabı [Piers-Harris's self-concept scale handbook for children]. Ankara: Türk Psikologlar Derneği Yayınları; 1996.

17. Kovacs M. Rating scale to assess depression in school aged children. Acta Paedopsychiatr 1981; 46:305-15.

18. Öy B. Çocuklar için Depresyon Ölçeği: Geçerlik ve güvenirlik çalışması [Depression Scale for Children: A validity and reliability study]. Türk Psikiyatri Dergisi 1991; 2: 132-6.

19. Spielberger CD. Preliminary Manuel for the State-Trait Anxiety Inventory for children. 1st ed. Palo Alto: Consulting Psychologists Press, 1973. [Crossref]

20. Özusta Ş. Çocuklar için Durumluk-Sürekli Kaygı Envanterìnin uyarlama, geçerlik ve güvenirlik çalışması [Adaptation, validity and reliability study of State-Trait Anxiety Inventory for children]. Türk Psikoloji Dergisi 1995; 10: 32-44.

21. Varni JW, Seid M, Rode AC. The PedsQL: measurement model for the pediatric quality of life inventory. Med Care 1999; 37: 126-39. [Crossref]

22. Memik NÇ, Ağaoğlu B, Coşkun A, Karakaya I. Çocuklar İçin Yaşam Kalitesi Ölçeğinin 8-12 Yaş Çocuk Formunun Geçerlik ve Güvenirliği. Çocuk ve Gençlik Ruh Sağlığı Dergisi 2008; 15:87-98.

23. Zhou $Y H$, Hägg $U$, Rabie AB. Severity of dentofacial deformity, the motivations and the outcome of surgery in skeletal Class III patients. Chin Med J 2002; 115: 1031-4.

24. Dibiase AT, Sandler PJ. Malocclusion, orthodontics and bullying. Dent Update 2001; 28: 464-6. [Crossref]

25. Schwartz D, Dodge KA, Coie JD. The emergence of chronic peer victimization in boys' play groups. Child Dev 1993; 64: 1755-72. [Crossref]

26. Rossini G, Parrini S, Castroflorio T, Fortini A, Deregibus A, Debernardi CL. Children's perceptions of smile esthetics and their influence on social judgment. Angle Orthod 2016; 86: 1050-5. [Crossref]

27. Marques LS, Filogo^nio CA, Filogo^nio $C B$, Pereira LJ, Pordeus IA, Paiva SM, et al. Aesthetic impact of malocclusion in the daily living of Brazilian adolescents. J Orthod 2009; 36:152-9. [Crossref]

28. Bellot-Arcís C, Montiel-Company JM, Almerich-Silla JM. Psychosocial impact of malocclusion in Spanish adolescents. Korean J Orthod 2013; 43: 193-200. [Crossref]

29. Kragt $L$, Dhamo B, Wolvius EB, Ongkosuwito EM. The impact of malocclusions on oral health-related quality of life in children-a systematic review and meta-analysis. Clin Oral Investig 2016; 20: 1881-94. [Crossref]

30. Tessarollo FR, Feldens CA, ClossLQ. The impact of malocclusion on adolescents' dissatisfaction with dental appearance and oral functions. Angle Orthod 2012; 82:403-9. [Crossref]

31. Seehra J, Fleming PS, Newton T, Dibiase AT. Bullying in orthodontic patients and its relationship to malocclusion, self-esteem and oral health-related quality of life. J Orthod 2011; 38: 247-56. [Crossref]

32. Kenealy P, Frude N, Shaw W. An evaluation of the psychological and social effects of malocclusion:some implications for dental policy making. Soc Sci Med 1989; 28: 583-91. [Crossref]

33. Piers EV, Herzberg DS, editors. Piers-Harris Children's self-concept scale. 2nd ed. Los Angeles, CA: Western Physchological services; 2002. 
34. Bang YR, Park JH, Kim SH. Cut-Off Scores of the Children's Depression Inventory for Screening and Rating Severity in Korean Adolescents. Psychiatry Investig 2015; 12: 23-8. [Crossref]

35. Julian L. Measures of anxiety: State-Trait Anxiety Inventory (STAI), beck anxiety inventory (BAl], and hospital anxiety and depression scale-anxiety (HADS-A). Arthritis Care Res 2011; 63: 467-72. [Crossref]

36. Dahong $X$, Xiangrong C, Ying L, Yusong L, Ying G, Yan S. Effect of incisor position on the self-perceived psychosocial impacts of malocclusion among Chinese young adults. Angle Orthod 2013; 83: 617-22. [Crossref]

37. Jung MH. An evaluation of self-esteem and quality of life in orthodontic patients: Effects of crowding and protrusion. Angle Orthod 2015; 85: 812-9. [Crossref]
38. Baram D, Yang Y, Ren C, Wang Z, Wong RWK, Hägg U, et al. Orthodontic treatment need and the psychosocial impact of malocclusion in 12-year-old Hong Kong children. ScientificWorldJournal 2019; 2019: 2685437. [Crossref]

39. Gavric A, Mirceta D, Jakobovic M, Pavlic A, Zrinski MT, Spalj S. Craniodentofacial characteristics, dental esthetics-related quality of life, and self-esteem. Am J Orthod Dentofacial Orthop 2015; 147: 711-8. [Crossref]

40. Sharma A, Mathur A, Batra M, Makkar DK, Aggarwal VP, Goyal N, et al. Objective and subjective evaluation of adolescent's orthodontic treatment needs and their impact on self-esteem. Rev Paul Pediatr 2017; 35: 86-91. [Crossref] 